\title{
INTERMEDIALIDAD Y AUTO-REPRESENTACIÓN EN EL DOCUMENTAL CUBANO DE VANGUARDIA: EL CASO DE NICOLÁS GUILLÉN LANDRIÁN
}

Santiago JUAN-NAVARRO

Florida International University

navarros@fiu.edu

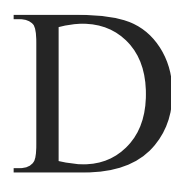

esde el comienzo del presente siglo se ha venido produciendo un boom del cine documental cubano realizado con pocos recursos y de forma independiente. La nueva generación de realizadores rompe con el discurso hegemónico, que durante cinco décadas había empleado el documental como arma de propaganda, y propone, por el contrario, un espacio discursivo abierto marcado por la reflexividad formal y la heterodoxia política. Estos cambios no surgen obviamente de la nada, sino que pueden rastrearse ya en el documental cubano de vanguardia de los años 60. De hecho, es significativa la figura tutelar de Nicolás Guillén Landrián en la producción de las nuevas generaciones de realizadores. El que fuera enfant terrible del Instituto Cubano de Arte e Industrias Cinematográficos (ICAIC), trabajó dos estilos que tendrían su impronta muchas décadas después de haber sido silenciado: uno de corte antropológico en el que mostraba de forma poética y contemplativa la vida cotidiana de los grupos subalternos, dentro de un contexto cada vez más marcado por la intolerancia; y otro de naturaleza vanguardista signado por el montaje frenético, el cine-collage y el contrapunto intermedial, que remedaba el estilo del primer Santiago Álvarez, pero socavando con ironía el mensaje ideológico de los documentales didácticos. Es esta última tendencia en su dimensión autorreflexiva la que analizaré en mi ensayo.

\section{Guillén Landrián: malditismo y experimentación}

La vida y la obra de Guillén Landrián estuvieron íntimamente relacionadas con las artes visuales, la experimentación, el inconformismo y el espíritu de rebeldía. Hijo de un abogado y sobrino del poeta Nicolás Guillén, estudió ciencias sociales en la Universidad de La Habana, donde participó en la lucha contra Batista. Su verdadera pasión, sin embargo, fueron la pintura y el cine. Tras el triunfo de la Revolución, entró en el ICAIC a instancias de su amigo Juan Carlos Tabío. Empezó como asistente de producción y allí conoció a Joris Ivens, que pronto se convertiría en su mentor. Al igual que Theodor Christensen (otra de sus figuras tutelares), Ivens había sido invitado por el ICAIC para formar la escuela de documentalistas que creció a la sombra de la Revolución. Salvo en un caso aislado, fue 
obligado a firmar todos sus documentales como Guillén Landrián. Parece que desde el principio se quería evitar toda confusión entre «el poeta nacional de Cuba» (fundador de la Unión de Escritores y Artistas de Cuba [UNEAC] y uno de los bastiones del oficialismo cultural revolucionario) y su sobrino «pródigo», al que sus colegas y amigos solían referirse como Nicolasito. Sus primeros trabajos (Patio arenero, Homenaje a Picasso y Congos reales) fueron cortometrajes didácticos realizados para la Enciclopedia Popular, que, bajo la dirección de Fernando Villaverde, acababa de crear el ICAIC en mayo de 1961 como «contribución al Año de la Educación» (García Borrero, 2012).

Al poco de entrar en el ICAIC, y cuando ya había cosechado premios en Festivales Internacionales por sus cortometrajes, las autoridades lo acusaron de intentar salir del país sin autorización y fue sentenciado a dos años en el Presidio Modelo de Isla de Pinos (el mismo al que en 1953 había ido a parar Fidel Castro junto a los demás asaltantes del Moncada). Tras un año de encierro desarrolló problemas nerviosos que lo obligaron a cumplir el resto de la sentencia bajo arresto domiciliario, pero no sin antes ser confinado en el Centro Psiquiátrico José Galigarcía, donde fue sometido a múltiples sesiones de terapia electroconvulsiva sin anestesia (Brown y Lago, 1991: 68). Paradójicamente, en 1966 el ICAIC volvió a contratarlo. Es entonces cuando realiza su documental más conocido y polémico: Coffea Arábiga (1968). Dicen que algunos se escandalizaron ante la escena que mostraba a Fidel ascendiendo al podio de la Plaza de la Revolución mientras se escuchaba de fondo la canción de los Beatles, «Fool on the Hill». Lo ocurrido, como veremos, fue bastante más complejo. En 1970, Guillén Landrián fue arrestado de nuevo y recluido en la Prisión Combinado del Este en La Habana. Un año después dirigió sus últimos cortometrajes, que no llegarían a ver la luz hasta treinta años después. En 1972, el ICAIC lo expulsó definitivamente del Instituto porque sus filmes eran «inconsistentes» con los fines de la Revolución. Sin la posibilidad de trabajar en la industria cinematográfica, se vio obligado a desempeñar todo tipo de empleos. En 1976 fue acusado de «desviacionismo ideológico» y de conspirar para asesinar al Líder Máximo. Llevado a Villa Marista en La Habana, estuvo retenido sin cargos y fue interrogado durante seis meses. En 1977 un Tribunal Militar lo envió de nuevo al hospital de Combinado del Este. Con su salud debilitada fue transferido, a petición de la Seguridad del Estado, al pabellón Carbó-Serviá del Hospital Psiquiátrico de la Habana (Mazorra), donde se le volvieron a aplicar electroshocks. Muchos de los detalles de su experiencia carcelaria y psiquiátrica aparecen consignados en el libro de Charles J. Brown y Armando Lago, The Politics of Psychiatry in Revolutionary Cuba (1991), en el que su caso ocupa un lugar prominente, y en la correspondencia que mantuvo con Manuel Zayas poco antes de morir en 2003; pero resulta significativo el enseñamiento del régimen con un cineasta cuyo único crimen fue el de realizar un cine muy subjetivo y personal. A finales de 1989 se le permitió emigrar a Miami, donde pasó el resto de su vida pintando, viviendo de motel en motel y frecuentando los ambientes marginales de la ciudad, que retrató en el documental Inside Downtown (2001).

Muy probablemente el revival de Guillén Landrián habría que atribuirlo al volumen especial editado por Paulo Antonio Paranaguá con ocasión de una muestra de cine cubano en el Centro 


\section{Tropelías. Revista de Teoría de la Literatura y Literatura Comparada, 27 (2017) 93 \\ Intermedialidad y auto-representación en el documental cubano de vanguardia: el caso...}

Pompidou de París (1990), y que contenía un ensayo de José Antonio Évora, en el que este llegaba a afirmar:

Si l'on venait à me demander quel est selon moi le meilleur documentaire sorti des laboratoires de 1'ICAIC durant ces trente ans, je choisirais sûrement Coffea Arábiga de Nicolás Guillén Landrián. Voilà une œuvre faite sur commande — sur la culture du café— dans laquelle le réalisateur a subordonné le sujet à son désir de faire une radiographie de l'esprit national enflammé par l'agitation révolutionnaire, autant dire un exact portrait du pays (1990: 130).

Irónicamente las declaraciones de Évora aparecían en un ensayo titulado «Santiago Álvarez et le documentaire». Que Évora reivindicara la obra de un cineasta perseguido y censurado como Guillén Landrián debió de provocar malestar en la directiva del ICAIC; que la llegara a considerar por encima de la del más celebrado y oficialista de los realizadores cubanos era toda una provocación o, al menos, una llamada a reconsiderar la historia del cine cubano.

Pero la rabiosa modernidad de sus filmes ha hecho que, a pesar del silencio y la censura, se hayan convertido, varias décadas después, en referente obligado del nuevo cine independiente en la isla y en uno de los nombres más valorados del documental cubano de todos los tiempos. Dean Luis Reyes relata así el impacto que tuvo la presentación de una retrospectiva sobre Guillén Landrián durante la Muestra de Jóvenes Realizadores, el 22 de febrero de 2003 en La Habana:

Aquella tarde, el lunetario del cine Charles Chaplin estaba salpicado de gente; los tumultos de años recientes eran más bien raros durante las primeras Muestras de Nuevos Realizadores. El programa fílmico de ese día incluía cinco cortos de Nicolás Guillén Landrián. Pero cuando empezó a exhibirse Desde La Habana i1969! Recordar hubo una conmoción. La violencia de su estilo de montaje, la complejidad de su estructura para proponer una lectura transversal de la historia cubana, más su sutil imprecación de los dogmas aplicados a la valoración de la experiencia del presente significó poco menos que un shock. La sensación general acabó siendo que la historia del cine cubano había sido mal contada (Reyes, 2013).

Para entender cabalmente este tardío impacto, así como su silencio previo, es necesario revisar el marco cultural y el ambiente político en el que se gestó su filmografía.

\section{Los orígenes del documental cubano de vanguardia}

Gran parte del cine de los años 60 en Cuba se caracterizó por una constante experimentación con las formas, puestas al servicio de una agenda política. A la manera de los agitprops soviéticos e invocando a Dziga Vertov y su «montaje materialista» (Deleuze, 1984: 81), se intentaba alcanzar una síntesis entre vanguardia artística y vanguardia política (Alea, 1969: 22-27). El modelo paradigmático del documental de aquellos años lo establece Santiago Álvarez en cortometrajes como Now (1965), Hanoi, martes 13 (1967), LBJ (1968) y 79 primaveras (1969), donde se vale de una concepción dinámica del montaje, integrándola dentro de un estilo propio con técnicas del cine de animación. En lugar del voice over, su cine recurre al texto, bajo la forma de intertítulos o dispositivos gráficos, así como a fotos, titulares periodísticos, dibujos y recortes publicitarios. El cine documental de Álvarez (al menos el que ensayó en la segunda mitad de los 60) no solo está influenciado por lo que John Mraz (1990: 131) ha llamado el montaje «dramático» (en la línea de Sergei Eisenstein), sino también por el 
uso compulsivo del collage intermedial que tiene sus raíces en la obra y el programa fílmico-político del otro gran representante de las vanguardias soviéticas: el mencionado Vertov. Como en la llamada teoría del «cine-ojo», el impacto de los documentales de Álvarez se basa principalmente en la yuxtaposición violenta de imágenes que produce en el espectador un shock cognitivo y emocional. María Luisa Ortega resume el mecanismo central del cine de Vertov de una forma que nos permite entender también los documentales que Álvarez hizo en aquellos años: «frente al montage, al intervalo, entendido como la puesta a distancia entre dos imágenes consecutivas, Vertov ponía en correlación dos imágenes lejanas (inconmensurables desde el punto de vista de nuestra percepción humana)» (2009: 112).

Valiéndose de su experiencia anterior en la radio y de la que fue pronto adquiriendo como director del Noticiero ICAIC, Álvarez recurre frecuentemente también a la banda sonora como soporte del ensamblaje visual y marcador del ritmo en la edición. La expresión más radical de este uso de un cine-collage al servicio de la música es Now, construido sobre fotografías recortadas de las revistas norteamericanas mediante un montaje dinámico de imágenes yuxtapuestas a la letra de la canción homónima de Lena Horne. La duración del filme (seis minutos) es exactamente la misma de la canción, lo que, unido, al uso de las técnicas del montaje dinámico hace que se hable de él como precursor del vídeo musical (Rist, 2007). Producido en 1965, Now parece un compendio de las preocupaciones del periodo. No es tan solo una denuncia de la opresión y el racismo en la sociedad norteamericana, sino también una convocatoria a la lucha dentro de una estética que une arte e ideología con gran virulencia y efectividad. El uso de tales técnicas continuará en el resto de los documentales realizados a finales de los 60. En ellos la disociación de imagen y sonido funciona a menudo como contrapunto sarcástico y/o lírico en su denuncia del imperialismo.

Si 1966 había sido el 'Año de la Solidaridad', 1967 fue el del 'Año del Vietnam Heroico' y el momento, por tanto, en que alcanza su máximo apogeo el énfasis en el internacionalismo y la lucha armada. Gran parte de la producción cultural del momento parece responder a la convocatoria de Che Guevara en su «Mensaje a la Tricontinental» a «crear dos, tres, muchos Vietnams» (Valle Dávila, 2013: 44). Como correa de transmisión política en el audiovisual, el ICAIC se hizo eco de este llamado. La estructura de Hanoi, martes 13 subraya, así, la tenacidad del pueblo vietnamita frente a la agresión exterior. De manera similar, 79 primaveras es una elegía de veinticinco minutos a Ho-Chi-Min, tras su muerte acaecida en 1969. Como el de Vertov, el cine de Álvarez no encubre las marcas del montaje, sino que las subraya dentro de una metatextualidad abierta. La implosión final en 79 primaveras exhibe las entrañas de la película en un vertiginoso proceso de rearticulación y reinterpretación de los signos propio de la época. Pero la heterogeneidad formal no es precisamente en el caso de Santiago Álvarez sinónimo de heterodoxia ideológica. La música e imágenes aparentemente polisémicas se construyen siempre dentro de un estrecho mensaje político, que no oculta nunca su carácter propagandístico, tendencioso y maniqueo, hasta el punto de que en otro de sus cortos, Despegue a las 18:00 (1969), Álvarez advierte al comienzo: «Van a ver un film didáctico, informativo, político y ... ipanfletario!». 


\section{Tropelías. Revista de Teoría de la Literatura y Literatura Comparada, 27 (2017) \\ Intermedialidad y auto-representación en el documental cubano de vanguardia: el caso...}

Como todos los documentales cubanos del momento, los de Álvarez estaban anclados en la contingencia y fueron elaborados con medios escasos, apresuradamente y con una finalidad didáctica. La conciencia que los cineastas cubanos tenían de la limitaciones técnicas impuestas tanto por la urgencia política como por los imperativos económicos del momento dieron lugar a las teorías de Julio García-Espinosa que consignó en su manifiesto «Por cine imperfecto» (1969). Como la «estética del hambre» de Glauber Rocha en Brasil y el «cine-guerrilla» de Octavio Getino y Fernando Solanas en Argentina, el cine cubano debía huir de la perfección técnica y el esteticismo (generalmente etiquetados de pequeño-burgueses o reaccionarios) para recurrir a la apropiación de imágenes y sonidos foráneos, puestos al servicio de un discurso crítico y beligerante que no hacía sino reflejar el clima de convulsión política y violencia que vivió Latinoamérica durante la Guerra Fría. Los experimentos del cine-collage evocaban los realizados por Vertov, Pudovkin y otros miembros de la vanguardia soviética (Arthur, 2000: 61), pero eran también soluciones creativas incentivadas por la escasez de recursos y materiales. Una de las técnicas más comunes en el documental de estos años (y que veremos exacerbada hasta el histrionismo en los últimos documentales de Guillén Landrián) es el trabajo intermedial sobre los significantes de las palabras y los signos para llamar la atención sobre su significado, pero también sobre su materialidad. Una misma consigna o palabra se repetía de forma intencional hasta ocupar toda la pantalla mediante zooms rápidos o aumentos bruscos de tamaño. Un mismo sonido, generalmente en contrapunto con las imágenes, podía reaparecer recurrentemente, creando una dinámica de asociaciones dialécticas. Todo ello se encuadraba en actos de fuerte violencia visual y sonora que buscaban agitar al espectador convocándolo a la acción.

Las representaciones más agudas de las contradicciones de la sociedad cubana de esos años, sin embargo, corrieron a cargo de cineastas menos apremiados por las circunstancias del momento y menos dados, por tanto, al servilismo ideológico. Sara Gómez y Nicolás Guillén Landrián, dos de los pocos realizadores afrocubanos que han trabajado para el ICAIC, fueron quienes mostraron una mayor sensibilidad para retratar las vidas de los seres marginales. Sus obras nunca llegaron a encuadrarse dentro de la euforia y la ortodoxia políticas vigentes, de ahí que, a menudo, fueran archivadas, prohibidas y purgadas de la filmografía oficial. Como veremos, el cine de Guillén Landrián, especialmente sus últimos documentales, explota muchas de estas estrategias. Pero si en el caso de Santiago Álvarez este repertorio se ponía invariablemente al servicio incondicional de una propaganda política que no dejaba espacio a la crítica, al cuestionamiento o a la duda, Guillén Landrián hará precisamente de la ambigüedad y la ironía, la base de su estética.

No está del todo claro por qué, a finales de los 60, Guillén Landrián fue readmitido al ICAIC ${ }^{1}$. Para esas fechas tres de sus títulos habían sido censurados y ya había recorrido una buena parte de los

\footnotetext{
${ }^{1}$ Esta es la versión que el propio director da en una de sus cartas a Manuel Zayas: «A mí me meten preso. Por razones ideológicas, decían ellos. Me mandan para Isla de Pinos y me dan electroshocks. Después de haber estado preso, les dije a ellos que yo no tenía otra cosa que hacer: o me quedaba en la industria de cine o les pedía el favor que me dejaran salir del país. Entonces me dijeron que no, que me quedaba dentro de la industria de cine y me dieron a hacer Coffea Arábiga» (2010). Su última esposa (Gretel Alfonso) menciona la intercesión de Christensen (Ramos, 2013) y Dean Luis Reyes sugiere la de su tío, el poeta Nicolás Guillén, entonces presidente de la Unión Nacional de Escritores y Artista de Cuba (UNEAC) (2010: 47); pero resulta difícilmente comprensible que alguien que había sufrido de forma tan intensa la
} 
centros penitenciarios y hospitales psiquiátricos del país. En 1968, sin embargo, se le asigna al Departamento de Documentales Científico-Populares, en un intento quizá de controlar su temperamento creativo, a veces desbocado. Lo cierto es que los cortometrajes que realizó a partir de ese momento tienen muy poco de científico y no pudieron llegar a ser nunca populares, porque o bien fueron prohibidos, o no llegaron a tener más que una corta vida.

El cine posterior al encierro y los electroshocks se caracteriza por una ruptura estética con su obra anterior. El montaje en ellos se hace menos lineal y más asociativo e intelectual, en la línea de Vertov y, al menos formalmente, en sintonía también con lo que en esas mismas fechas estaba haciendo Santiago Álvarez. Pero, a diferencia de la certidumbre ideológica que transmiten los documentales de Álvarez, en los de Guillén Landrián hay una búsqueda imposible de una totalidad que termina por revelarse como caótica y fragmentada. La calidez que se desprendía de sus cortos antropológicos da paso a la frialdad y cierto distanciamiento irónico que tuvo que ser necesariamente encubierto bajo un barniz de impostado entusiasmo. El montaje relativamente lineal y el tempo a veces pausado de su trilogía sobre la Cuba rural —Ociel del Toa (1965), Retornar a Baracoa (1966) y Reportaje (1966)_ fueron reemplazados por asociaciones sorprendentes, inverosímiles y, a menudo, irracionales. Más que reflejar un giro voluntario en el estilo del autor, estos cambios fueron también el reflejo del creciente clima de agitación revolucionaria que habría de desembocar tanto en la locura colectiva del país como en el desequilibrio mental del propio director. También indican un cambio en las tendencias dominantes de la cinematografía cubana, ya que a finales de los 60 el neorrealismo había sido definitivamente abandonado como referente estético (Elena, 2006: 73), siendo reemplazado por una búsqueda desenfrenada de lo nuevo y sorprendente. Sus cortometrajes responderán a partir de entonces a un estilo hiperdinámico, casi convulsivo, cuando no incoherente e incluso perturbador. No queda aquí apenas rastro de la poesía, sutileza y «regodeo estético», que Zayas atribuye a sus primeros cortometrajes (2010: 125). Incluso cuando algunos fragmentos de estos reaparezcan de nuevo, reciclados (fig. 1) en un claro desafío a los censores, lo harán dentro de una estética del collage, los contrastes bruscos y el histrionismo, que, hoy día (aunque no en su momento), podría leerse como parodia del modelo fílmico hegemónico de aquellos años.
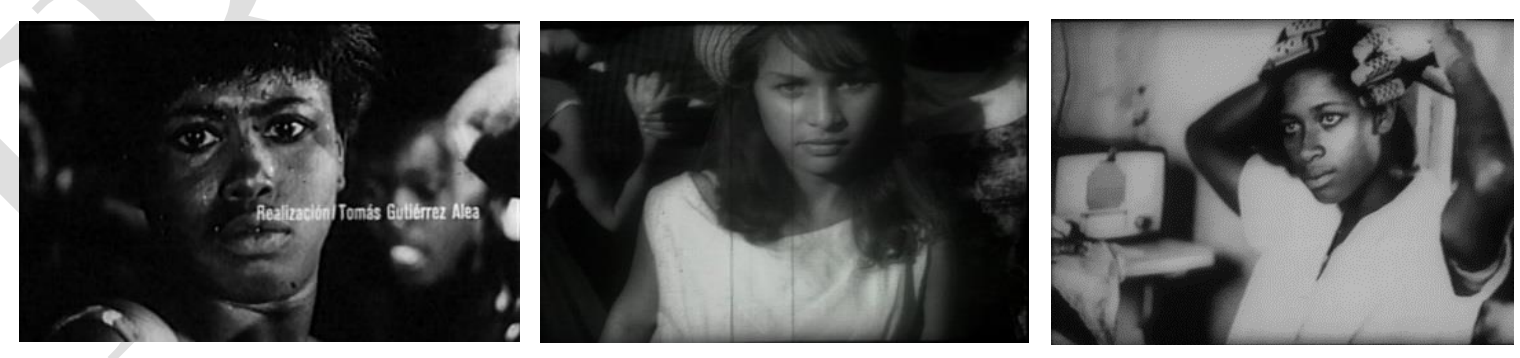

Figura 1. Metrajes reciclados en la obra de Guillén Landrián. A la izquierda, fotograma de la secuencia inicial no acreditada de Memorias del subdesarro (Tomás Gutiérrez Alea, 1968) incluida en Desde la Habana y planos procedentes de dos de sus filmes censurados: Reportaje (centro) y Retonar a Baracoa (derecha), ambos reutilizados en Coffea Arábiga.

represión política y la marginación social fuera readmitido en un Instituto que en muchos momentos de su historia actuó como baluarte de la propaganda cultural del régimen. 


\section{Coffea Arábiga (1968) y el desmontaje del documental didáctico revolucionario}

El primer encargo que recibe a su regreso al ICAIC es la dirección de un documental didáctico sobre el Plan del Cordón de La Habana para la siembra masiva del café. Filmado en 1968, Coffea Arábiga, de dieciocho minutos de duración, celebra la movilización masiva de voluntarios para plantar café en los alrededores de la capital. Aunque el Cordón de La Habana pasó a la historia como una versión pobre de la Zafra de los Diez Millones, fue promocionado de forma similar en su tiempo. El rotundo fracaso del Plan habría de pasar factura al cineasta y, como veremos, transformaría lo que inicialmente fue concebido como exaltación patriótica del idealismo de una época (el cineasta lo calificó como «un acto de amor») en la burla de un proyecto disparatado. El filme probablemente no es, en última instancia, ninguna de las dos cosas (ni un filme de propaganda ni una sátira del cine de propaganda), si bien las dos tendencias parecen coexistir en una dialéctica esquizofrénica que se repetiría, con mayor fuerza si cabe, en su siguiente cortometraje.

El prólogo se abre con la imagen del círculo solar y del romper de las olas sobre un acantilado mientras escuchamos la voz del otro Nicolás Guillén (el poeta) recitando los versos de uno de sus más célebres poemas: «Junto a la orilla del mar,/ tú que estás en fija guardia,/ fíjate, guardián marino,/ en la punta de las lanzas/ y en el trueno de las olas/ y en el grito de las llamas/ y en el lagarto despierto/ sacar las uñas del mapa:/ un largo lagarto verde,/ con ojos de piedra y agua». A continuación se ofrece un breve resumen de los orígenes de la plantación del café en Cuba y del papel de los esclavos africanos, para pasar de nuevo a repetir de forma idéntica las mismas imágenes iniciales y los mismos versos. Solo entonces, con un fondo de música bebop, arrancan los créditos del filme. En menos de dos minutos el prólogo establece prolépticamente los rasgos dominantes del cortometraje: el montaje dinámico que combina escenas documentales, datos estadísticos, rótulos didácticos (pero también irónicos o provocativos), historia política, detalles antropológicos y un exaltado aliento poético basado en fuertes contrastes visuales y sonoros; todo ello al ritmo de un tempo frenético que ya anuncian la descarga jazzística de los créditos.

Se suceden inmediatamente imágenes de las plantaciones de café, eslóganes propagandísticos («si ayer fue heroico combatir en la sierra y en el llano, hoy es heroico transformar la agricultura»), y un detallado informe de un ingeniero sobre el método de la siembra directa ${ }^{2}$. El dinamismo de la imagen, con atrevidos juegos tipográficos contrasta aquí con un contenido presuntamente 'científico' y, ante todo, pedagógico. La ironía pronto hace su aparición de forma provocadora. El aburrido informe es presentado como un dictado, con su inevitable «punto final». Por si no hubiera quedado claro, asistimos seguidamente a una emisión de Radio Cordón de La Habana, donde se retoman las instrucciones para el cultivo del café. «¿Sabes tú lo que es un umbráculo?» La emisión de radio explica nuevos detalles de las técnicas agrícolas. Pero el estilo cambia de nuevo abruptamente para adoptar la estética típica del cinéma vérité, aunque presentado aquí en clave paródica. Simulando una entrevista casual en la Calle Línea de La Habana («iOIGA!» clama un intertítulo), se le pide a una transeúnte su

\footnotetext{
${ }^{2}$ En Coffea Arábiga no hay narración tradicional. Las voces en off están deformadas por el eco, el tono o el ritmo de la alocución imitando a los escolares que repiten una lección para memorizarla.
} 
opinión sobre la campaña. La mujer, que resulta ser la entonces compañera de Guillén Landrián, Dara Kristova, repite literalmente en búlgaro las instrucciones que acabamos de escuchar poco antes en la radio oficial. El efecto desconcertante de la secuencia se acrecienta mediante una sucesión de primeros y primerísimos planos del rostro fragmentado del personaje montados al ritmo de la música de Diana Ross and the Supremes: «Set me free, why don`t you, babe? Get out of my life, why don’t you babe?». En el contexto de la producción del filme, la brevísima secuencia pudo ser interpretada como una indicación más de la participación de la nueva mujer cubana en el Plan, con su consiguiente emancipación de las tareas domésticas. En el contexto, en cambio, del fracaso de la campaña, estos planos adquieren inevitablemente un tono burlesco. Aquí el narratario de la canción no parece ser ya 'el compañero', sino un Estado que ha terminado por convertir el trabajo 'voluntario' de las mujeres en una nueva forma de explotación al servicio de una causa absurda; un Estado, que ha invadido el ámbito de lo privado sacrificando la identidad individual en aras de una abstracta causa colectiva, fuera de la cual nada tenía derecho existir. Ese «Get out of my life, why don’t you babe?» suena aquí a súplica, pero también a desafío de aquellos que, como Guillén Landrián, sufrieron las consecuencias de su 'conducta impropia'.
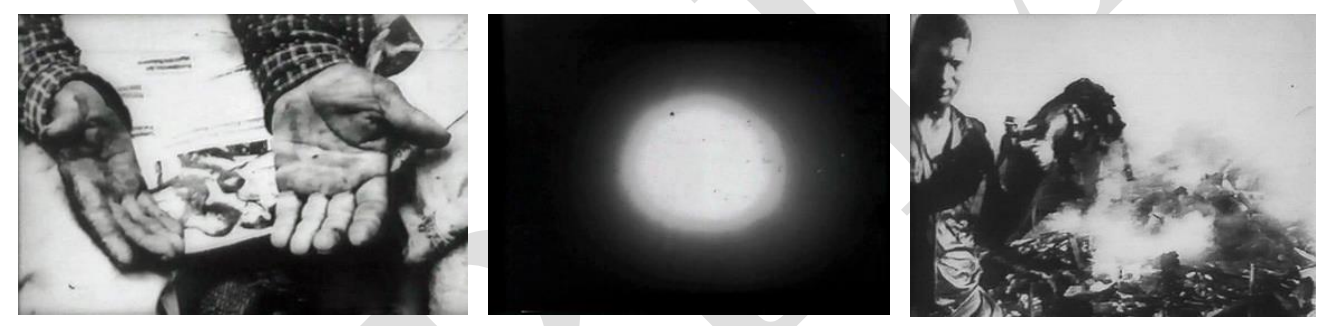

Figura 2. Ambigüedad y virulencia de las metáforas visuales en Coffea Arábiga

Pero el cuerpo del Coffea Arábiga los constituye el discurso didáctico, que va explicando con gran claridad los pasos para la producción del café: la preparación de la tierra, la aclimatación al sol, el riego, la limpieza de los sembrados, la fertilización, las enfermedades de la planta, la fumigación, la enumeración de las especies cultivadas en la isla, la cosecha, las fiestas campesinas, el funcionamiento de las plantas de beneficio, el tueste, la clasificación, el empaquetado, el etiquetado, las campañas de aumento de la producción y el consumo final del café en los bares y centros de distribución. El contenido no puede ser aparentemente más apropiado para la serie de «documentales científicopopulares» en la que se inscribe. La presentación formal de estos asuntos, por el contrario, está en las antípodas del género. A pesar de que, como he venido apuntando, Santiago Álvarez, había experimentado con el cine-collage de una forma radical, siempre lo había hecho poniendo todo el repertorio formal al servicio de la diatriba política y un mensaje político sectario. En el documental de Guillén Landrián, en cambio, los contrastes violentos de imagen y sonido se suceden de una forma desconcertante, en la que el cineasta parece luchar a cada paso con el encorsetamiento del género, dándole giros completamente imprevistos. Cuando se vale del modo expositivo (Nichols, 1997: 6872), lo hace solo para socavar sus certidumbres, mediante la inserción de planos o secuencias que responden a otros modos documentales radicalmente distintos (cuando no antitéticos). 
La técnica narrativa dominante en el documental se basa en el contrapunteo violento (y a menudo extravagante) de imagen y sonido. Tras la detallada descripción del proceso de cultivo del café, se inserta lo que parece ser un método de enseñanza del inglés, patrocinado para la radio por las marcas de café Tu-Py, Pilón y Regil. Una mujer recita con acento deficiente un texto trivial: «Christmas, it is Christmas and he is Santa Claus with his bag of toys. He brings toys for the children». Simultáneamente se van presentando imágenes de la vida en Cuba antes de la Revolución. Por un lado, mujeres de la alta burguesía asistiendo a fiestas y galas, entre las que se entrecruzan otras que muestran la miseria del campesinado. Una de las más recurrentes es la foto fija de unas manos encallecidas extendidas hacia el espectador, como en señal de súplica y que veremos reaparecer periódicamente en el filme. A la mención a Santa Claus y sus regalos sigue una explosión y la figura de un soldado que camina apresuradamente en dirección a la cámara (al espectador) portando lo que pronto reconocemos como un brazo amputado. La impactante secuencia, procedente de un Noticiario del ICAIC sobre el sabotaje del La Coubre, se repite hasta tres veces, una repetición que es interrumpida por una vuelta al mensaje publicitario: «¿Quieren Uds. tomar Café Regil? ¿Pilón? o ¿Tu-Py?», a lo que un coro anónimo contesta con un «iNO!» rotundo, seguido por la imagen de un bosque de fusiles en alto y el consabido lema: «PRIMERO DEJAR DE SER, QUE DEJAR DE SER REVOLUCIONARIO!», que será también reciclado en su siguiente cortometraje (fig. 6). Bruscamente el filme retoma el tono expositivo de manual didáctico detallando los problemas de las enfermedades de las plantas y la necesidad de fumigación.

Este provocador juego de contrapuntos vehementes entre lo trascendente y lo trivial, lo trágico y lo cómico, lo pretencioso y lo burlesco, alcanza su punto álgido en la secuencia más polémica del filme: aquella que muestra a Fidel Castro en una sucesión semejante de superposiciones anacrónicas que llevó a muchos a pensar que fueron las que provocaron la caída en desgracia final del director. En la secuencia aparece por primera vez el Comandante encaminándose al estrado donde va a pronunciar uno de sus habituales discursos en la Plaza de la Revolución ${ }^{3}$. Mientras asciende se escuchan los consabidos gritos de las masas concentradas en la plaza (¡Fidel! ¡Fidel!) y la imagen corta a un primerísimo plano de su barba, que mediante un fundido encadenado se va convirtiendo en una planta florecida de café. Se empiezan a escuchar los acordes de «Fool on the Hill» de los Beatles. En el tramo final del cortometraje veremos repetida la ascensión del Comandante en dos ocasiones. En la primera, lo que parecía ser el clímax (la apoteosis de la campaña cafetalera), se convierte en algo puramente anecdótico, al ser seguida de una retransmisión radiofónica que nada tiene que ver con el tema: «Desde Baracoa, zona cafetalera de Cuba, territorio libre de América, transmite CMDX Radio Baracoa». El programa en este caso no tiene ningún contenido didáctico, ni contribuye a reforzar el mensaje ideológico del filme en el que se inscribe. Todo lo contrario. Se trata de un fragmento tomado íntegramente de uno de sus anteriores documentales censurados (Retornar a Baracoa) donde una mujer negra se arregla el pelo mientras escucha un poema ridículamente cursi en la radio (fig. 1): «La vida pasa. La vida rueda. Quizá se aparten tu alma y la mía. Pero el recuerdo nace y se queda. Y,

\footnotetext{
${ }^{3}$ Las imágenes están tomadas del cortometraje Asamblea General (1962), de Tomás Gutiérrez Alea (Reyes, 2010: 52).
} 
aunque nuestro deseo no retroceda y nuestra llama se apague un día, mientras yo pueda soñar pueda regar mis sueños en la vereda de la harmonía, tendré la dulce melancolía de aquellas frases entre la umbría y aquellos besos en la alameda». La secuencia carece por completo de cualquier mensaje político, aunque es precisamente su inserción en este contexto lo que hace que cobre uno, pero muy distinto a la euforia revolucionaria que supuestamente debía transmitir la película. Organizado sobre una sucesión de fotos fijas, que evoca la técnica de Chris Marker en La jetée (1962), el segmento rememora poéticamente un momento trivial en la vida privada de una mujer que parece vivir al margen de la locura colectiva del país en esos momentos: «En Radio Baracoa hemos presentado Una cita contigo; un programa con versos y canciones para ti». Lo que en un principio estaba llamado a interpretarse como una estampa de la Cuba pre-revolucionaria 'felizmente' dejada atrás con el triunfo de la Revolución, se convierte, para el espectador familiarizado con la obra de Guillén Landrián en un intertexto polisémico cargado de ironía. Al saber que se trata de unas imágenes rodadas en el Oriente cubano cuando ya el delirio revolucionario estaba en pleno apogeo y que formaban parte de un filme prohibido (Retornar a Baracoa), donde se subrayaba el carácter incompleto de la Revolución y la indiferencia de la población rural, el espectador es convocado a reevaluar su sentido aparente.

A este primer intertexto, que nos remite a su obra censurada, sigue en contrapunto un aluvión de consignas («PRODUZCAMOS VEGETALES PARA NUESTRO PUEBLO»), carteles propagandísticos («La mujer de AVANZADA a la AGRICULTURA»), pronósticos triunfalistas («iORIENTE VA A LLENAR 19 MILLONES DE LATAS DE CAFE ESTE AÑO! GRANO A GRANO») y marchas revolucionarias: («iY el pueblo sigue adelante! ¡Libertad! ¡Libertad! ¡Libertad!»). El clímax de este segmento, de nuevo, no viene dado por el consabido discurso de Fidel, sino por el baile (presente en casi toda la obra del cineasta), como manifestación espontánea de la alegría popular, del goce público: «EN ALGUNA ZONAS CAMPESINAS AL TERMINAR LA COSECHA SE DAN FIESTAS; Y ELLOS, LOS CAMPESINOS BAILAN» (la palabra «BAILAN» se agranda hasta ocupar toda la pantalla). Esto da lugar a la inserción de una nueva secuencia correspondiente a otro de los filmes censurados de la «Trilogía del Subdesarrollo»: Reportaje; en este caso, la hipnótica imagen ralentizada de una joven campesina bailando y mirando a cámara fijamente (fig. 1), «una de las escenas más sensuales del cine cubano», según Manuel Zayas (Ramos, 2010). De hecho, el resto de los planos de la secuencia repiten un patrón similar; en su mayor parte consisten en rostros de trabajadores bailando mientras miran a cámara, miradas que inevitablemente terminan por «romper la cuarta pared» del ilusionismo dramático, estableciendo así una complicidad con la audiencia, al margen del bombardeo propagandístico que rodea al intertexto (fig. 3$)^{4}$. La sutil desconexión de las imágenes con la música y el breve oasis de esparcimiento e intimidad en medio de

\footnotetext{
${ }^{4}$ El concepto 'ruptura de la cuarta pared', ha sido usado en la crítica para referirse a la acción de uno o varios personajes que interactúan con el público espectador revelando así el efecto de invisibilidad propio del cine clásico y el realismo dramático. Para un estudio detallado de los múltiples efectos resultantes de esta ruptura, véase el reciente estudio de Tom Brown (2013). Sus reflexiones son particularmente apropiadas en el caso del cine de Guillén Landrián, que usa este recurso con diferentes finalidades: romper el espejismo de objetividad en el documental, establecer una relación de intimidad con los personajes e incluso tematizar la reflexión sobre el acto de mirar que se desprende de sus cortometrajes.
} 
la histeria política colectiva, evocan por un momento la placidez de Ociel del Toa y otros cortometrajes de su filmografía temprana. Pero un nuevo cartel exige «más producción» y un montaje rápido repite la dinámica del cortometraje hasta ese momento: explicación didáctica de los últimos pasos en el tratamiento de los granos del café y su consumo en los bares y calles de La Habana. En algunas de las escenas rodadas en una de las fábricas sorprende el choque entre la estética futurista propia del cine Vertov, que se deriva de la repetición constante de imágenes de máquinas trabajando a pleno rendimiento y primerísimos planos en contrapicado de rostros de trabajadores, y las composiciones estáticas un grupos de otros posando ante la cámara. Todas estas rupturas de la cuarta pared, tan habituales en la cinematografía de Guillén Landrián, apuntan a la búsqueda de la implicación del espectador, como vía de escape a la disolución del Yo en lo colectivo, algo impensable en los documentales épico-doctrinarios.
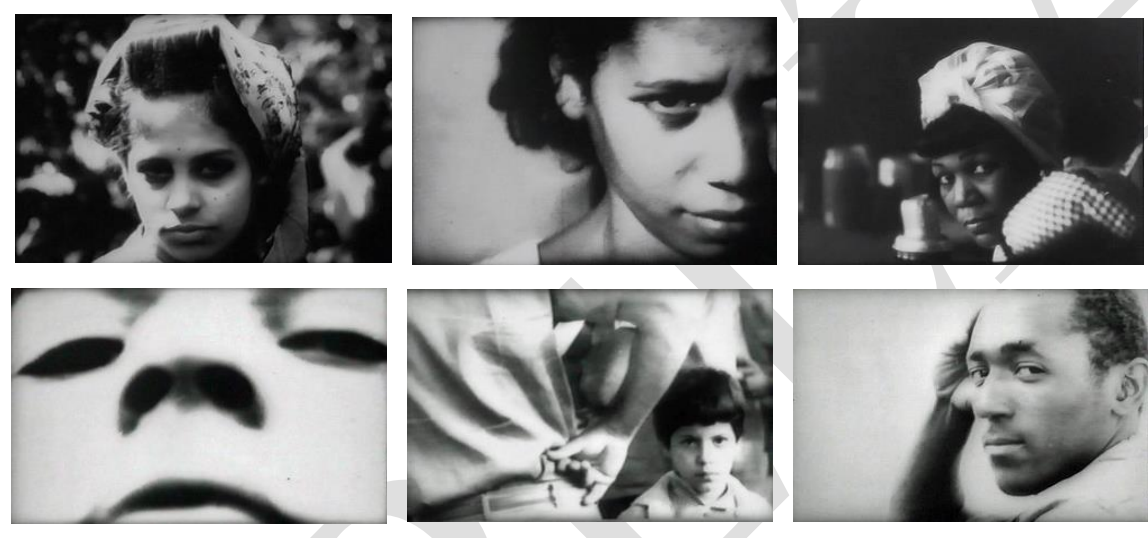

Figura 3. Ejemplos de ruptura de la cuarta pared en Coffea Arábiga

(algunos procedentes de los documentales censurados de su Trilogía Rural).

Si el prólogo funcionaba como mise en abyme proléptica (Dällenbach, 1977: 74, 95), el final actúa como analepsis intramedial - «espejo textual retrospectivo» en la terminología de Pethö (2003: 186) - que sintetiza temática y diegéticamente lo que hemos presenciado hasta ese momento. La conclusión consiste así en una vertiginosa sucesión de escenas climáticas y anticlimáticas. Reaparecen los motivos del prólogo (el sol radiante y las olas rompiendo contra la costa), seguidos del ascenso de Fidel a la tribuna de la Plaza, los negros bailando en un ritual de Santería y unos rótulos que transforman paródicamente la letra de una famosa canción: «en Cuba todos los negros y todos los blancos y todos tomamos café». La vista panorámica de una gran concentración popular repleta de banderas cubanas y pancartas y los intertítulos «Un momento por favor» / «Para terminar...» (giro típico empleado por el Líder Máximo en sus alocuciones públicas), hacen presagiar como clímax el esperado discurso; pero este nunca llega a pronunciarse. Por el contrario, los rótulos siguientes anuncian un final insólito: «Para terminar...»/ «LOS BEATLES»/ «EN»/ «The fool on the hill (El bobo sobre la colina)». Y se reproduce mediante subtítulos en español un fragmento de la letra de la canción de Los Beatles (entonces prohibidos en Cuba): «Todos creían que era un tonto el hombre que sobre la colina veía la tierra girar y el sol caer». Suena la canción, aunque no en sincronía con los subtítulos, y vuelven a aparecer dos leitmotivs icónicos del filme: las manos abiertas desplegadas ante 
el espectador y el sol (ahora poniéndose) al compás de la música. El cartel «Documentales científico populares» pone punto final al cortometraje.

Como señalé anteriormente, la estética de la ambigüedad y el valor polisémico de las técnicas de montaje de Guillén Landrián hace imposible concebir Coffea Arábiga como un texto estable susceptible de una lectura ideológica precisa. Pretender, como se ha pretendido, que fue concebido como una sátira de los delirantes proyectos del Comandante, sería absurdo (hubiera sido un suicidio). El propio Guillén Landrián reconoció en sus últimas entrevistas que nunca fue su intención hacer un filme anticastrista ni cuestionar tampoco (al menos abiertamente) el Plan del Cordón de La Habana. Menos aún ridiculizar a Fidel (algo tabú incluso en el discurso público de hoy día). De hecho, la canción de los Beatles podría recordar al espectador del momento que los escépticos y los enemigos del régimen habían usado estas mismas expresiones (bobo/loco) para describir a Fidel. Lo que ocurre es que la naturaleza inestable del texto hace que su interpretación varíe radicalmente en función del contexto político y cultural desde el que es interpretado. Esto es aún más obvio en el caso del cinecollage, al que claramente se subscribe Coffea Arábiga, construido sobre fragmentos heteróclitos que adoptan nuevos significados y se resisten a cualquier clausura semántica.

El caso es que el ICAIC pareció quedar inicialmente satisfecho con el documental, que fue promocionado, exhibido y llegó a representar a Cuba en festivales internacionales. Su desgracia (y la de su autor) fue que el Plan del Café fue un estrepitoso fracaso, lo que llevó al régimen a silenciar cualquier recuerdo de su memoria. El bombardeo mediático que había repetido consignas a diario durante toda la campaña y por todos los medios de comunicación (la prensa, la radio, los noticieros) dejó paso al más absoluto mutismo. Ante ese nuevo giro que tomaron los acontecimientos, el cortometraje, que anteriormente algunos habían considerado como una oda al idealismo revolucionario empezó a ser visto entonces como una burla y una traición. Pero, sobre todo, Coffea Arábiga se transformó en un objeto molesto que había que hacer desaparecer. Como tantos otros filmes cubanos, el de Guillén Landrián quedó así ‘archivado' en las bóvedas del ICAIC. Solo así podría explicarse que la carrera de su director en el Instituto no terminara allí, sino varios años después, en 1972, tras realizar otros documentales igualmente 'problemáticos' en lo ideológico, pero en un contexto en el que ya era inviable cualquier forma de expresión que no se atuviera a la estética social-realista impuesta por el Primer Congreso de Educación y Cultura (1971). Los políticos e intelectuales allí reunidos (con Santiago Álvarez a la cabeza del sector cinematográfico) abominaron de los experimentos formales y apostaron por un realismo popular y didáctico, «contrario a las tendencias de élite» (VVAA, $1971: 145)^{5}$.

\footnotetext{
${ }^{5}$ En su discurso de clausura, Fidel Castro dejó establecidos los nuevos principios que habrían de sustituir su anterior mensaje a los intelectuales y que se resumen en su primera consigna «El arte es un arma de la revolución» (VV.AA., 1971: 18). Ninguna forma de expresión artística que no respondiera a ese imperativo tenía cabida en el nuevo orden revolucionario. Como señala Robert Reed (1991: 135), el Congreso supuso el sello de aprobación de la Gran Purga emprendida años atrás, pero que alcanzó su apoteosis en 1971, prolongándose a lo largo del llamado Quinquenio Gris (1971-1976).
} 
Intermedialidad y auto-representación en el documental cubano de vanguardia: el caso...

\section{Figuras reflexivas de la intermedialidad en los últimos documentales de Guillén Landrián} (1969-1971)

Poco después de Coffea Arábiga, Guillén Landrián realizó Desde La Habana: ¡1969! Recordar (1969), un cortometraje aún más complejo y con un estilo todavía más desquiciado, que hace un repaso a toda la historia de Cuba, o más exactamente, a toda la metanarrativa del mito de la construcción de la nación cubana producida bajo el signo de la Revolución. Si su documental anterior integraba y acumulaba los logros formales de su obra precedente, Desde La Habana se vale de una intermedialidad desbocada para hacer un barrido tanto de la historia política del país como de sus representaciones (incluidas las llevadas a cabo por el propio realizador en sus experimentos anteriores). Su carácter totalizante (y a la vez fragmentario) podría incluso interpretarse formalmente como un intento imposible de sintetizar dentro de un cortometraje todos los modos posibles del documental: expositivo, observacional, poético, reflexivo y performativo (Nichols, 1997: 65-114), algo que atentaría contra la organicidad y coherencia del discurso afirmativo hegemónico del llamado Nuevo Cine Latinoamericano y muy especialmente del cine del ICAIC.

Desde La Habana recurre a una estructura semejante a la de Coffea Arábiga. El cortometraje arranca con un prefacio que responde a los parámetros de la intramedialidad especular: avanza una síntesis de lo que veremos a continuación, tanto desde el punto de vista formal como del contenido. Actúa, por tanto, como «espejo autotextual prospectivo»(Pethö, 2003: 186). La canción de los Beatles «Mother Nature's Son», cuyo id́lico texto se va reproduciendo en forma de subtítulos, sirve de fondo a la recurrente imagen de una explosión atómica que se repite a lo largo de la secuencia inicial (fig. 5). La banda sonora aparece pronto entremezclada con la estática de la radio, voces entrecortadas y la retrasmisión de la llegada del hombre a la luna. Todo ello apoyado con intertítulos y recortes de prensa del evento que cortan bruscamente a fotos del Holocausto seguidas rápidamente por otras de miembros de Ku Klux Klan, de un afroamericano desangrándose en la vía pública, de otro en una manifestación de protesta y de otros bailando en las calles. La eufórica retransmisión radiofónica del amerizaje en la luna («el hombre en uno de sus más grandes momentos») y el aire utópico de la canción de los Beatles («escuchando el bonito sonido/ de la música al volar») contrastan con el tono apocalíptico tanto de la amenaza nuclear como de las imágenes del mayor genocidio del siglo XX y de la marginación sufrida por la población negra en Cuba y EE.UU. La secuencia inicial termina con el comienzo de un discurso del Líder Máximo («Eliminar todo lo que nos divida al cumplirse este quinto aniversario») que sirve de fondo a grandes intertítulos que nos remiten a Coffea Arábiga: «VAMOS TODOS A LA GRAN SIEMPRE DE PRIMAVERA», «NOSOTROS ESTAMOS HACIENDO ALREDEDOR DE LA HABANA/ ¡UN CORDÓN!»). Solo entonces, y después de tres escasos minutos en los que el espectador ha sufrido un intenso bombardeo intermedial de imágenes y sonidos dispuestos a la manera del montaje asociativo, comienzan a rodar los créditos del filme.

La forma en que se presenta el título es particularmente significativa, pues aparece escindido por el primero de una larga serie de planos que muestran un celuloide dañado (como si hubiera sido revelado torpemente o maltratado con saña), lo que hace a menudo imposible distinguir lo representado 
(fig. 4). En este caso, además, el recurso tiene una dimensión metafórica de gran intensidad especular, ya que apunta a una de las posibles interpretaciones del filme: el abuso de la historia y las limitaciones de la memoria en el marco de un periodo en el que se revisó capciosa y sistemáticamente el pasado en busca de un origen mítico legitimador del presente político ${ }^{6}$. Así, el intertítulo «Desde La Habana: ¡1969!'», es seguido de un corte brusco a fotogramas en negro de celuloide dañado por un churre que salpica la pantalla y al que sucede un zoom de la palabra «Recordar» invadiendo el plano. Los signos de exclamación de la fecha subrayan la euforia (la histeria) de un periodo que hacía imposible una evocación ecuánime y distanciada de la historia. Por el contrario el pasado fue sometido por el castrismo a un reciclaje histriónico que el filme de Guillén Landrián hacía aún más caricaturesco al comprimir todo el devenir nacional a dieciocho escasos minutos.
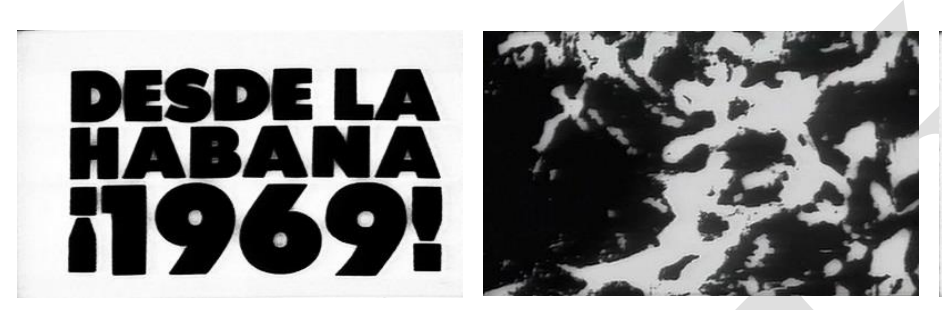

\section{RECORDAR}

Figura 4. Escisión del título del film mediante al interpolación de imágenes de celuloide dañado

Desde La Habana recurre a la repetición constante de las mismas imágenes y sonidos con más intensidad aún de lo que lo había hecho en su cortometraje anterior. Si visualmente la película presenta, mediante el trucaje, un celuloide estropeado, que deja entrever un sinfín de elementos visuales todavía más heterogéneos, la banda sonora reproduce en varias pistas sonidos dispares. El montaje se hace aún más sincopado. La sucesión de fotos fijas y planos cortos, además, se acelera de forma tan delirante que a veces rozan lo subliminal. Los sonidos, a su vez, se entrecruzan formando una cacofonía frecuentemente ininteligible. El repertorio de los temas representados se expande también de forma radical. No solo se revisa toda la historia nacional, también hay referencias al Holocausto, la represión de las manifestaciones en defensa de los derechos civiles en EE.UU., la llegada del Apolo 11 a la Luna, y una banda sonora que mezcla de forma aleatoria canciones populares, retransmisiones radiofónicas, anuncios publicitarios y las inevitables arengas de Fidel. Este discurso, organizado sobre la base de la repetición de fotogramas maltrechos y sonidos disonantes, produce el efecto de un eco caótico de imágenes oficiales y consignas, que son así desnaturalizadas ${ }^{7}$. El cortometraje intenta ir más allá de

\footnotetext{
${ }^{6}$ Recordemos que en 1968 se había puesto en marcha la llamada campaña de los '100 Años de Lucha' en la que equiparaban recurrentemente las Guerras de Independencia del siglo XIX con la Revolución del XX, dentro de un proceso de 'mitologización' de la historia que, aunque supuestamente se cerró en 1971, no ha cesado de caracterizar el discurso institucional hasta nuestros días (Juan-Navarro, 2008: 160).

7 En todos los cortometrajes que realizó a partir de Coffea Arábiga prevalece lo que Bill Nichols denomina una «reflexividad deconstructiva». En ellos «se alteran o rebaten los códigos o convenciones dominantes en la representación documental, dirigiendo la atención del espectador de este modo a su convencionalismo. No se hace tanto hincapié en los efectos del estilo como en los de la estructura, y aunque pueden intervenir estrategias estilísticas, el efecto principal consiste en una intensificación de la conciencia de lo que previamente había parecido natural o se había dado por supuesto» (1997: 110-11). Este elemento desnaturalizador tiene una importancia política capital en la obra de Guillén Landrián, ya que socavaba el criterio expositivo que terminó por imponerse en los documentales del ICAIC.
} 
los desafíos formales ensayados en Coffea Arábiga, sugiriendo (quizá inconscientemente) el efecto opresivo de la propaganda en la existencia diaria.
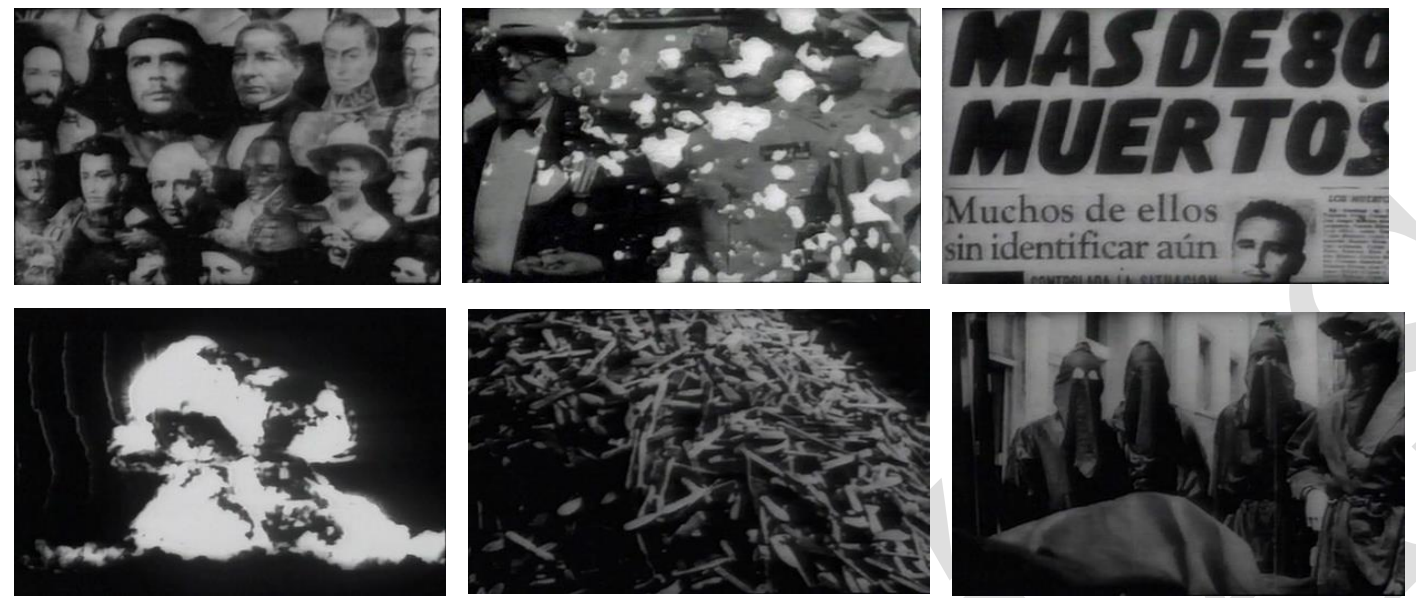

Figura 5. El devenir nacional/continental dentro de una visión apocalíptica de la Historia

Uno de los recursos más llamativos del filme es el reciclaje de secuencias censuradas (o no acreditadas) de algunos trabajos anteriores del cineasta. Desde La Habana incluye, por ejemplo, la secuencia inicial del filme cubano más famoso de todos los tiempos, Memorias del subdesarrollo (1968), de Tomás Gutiérrez Alea (fig. 1). De hecho, fue Guillén Landrián quien ideó dicha secuencia a partir de una experiencia que tuvo en los carnavales de La Habana. Pero tal y como confesó en una entrevista, la dirección del ICAIC no permitió que su nombre apareciera en los créditos (Zayas, 2010: 133). Se trata de las imágenes que abren la película y que muestran a la gente divirtiéndose al ritmo de mozambique («Teresa/dónde está Teresa...») interpretado por la orquesta de Pello el Afrokán. Se produce un disparo y un hombre cae muerto, pero pronto todos se olvidan del incidente y la gente sigue bailando con el mismo entusiasmo y la misma música. El goce domina sobre la tragedia. Irónicamente se trata de la secuencia de los créditos, entre los que, por supuesto, no hay ni rastro de su nombre. La escena, además, se inserta inmediatamente después de una ofrenda floral a Camilo Cienfuegos, de un discurso de Fidel en el décimo aniversario de la Revolución y de otro en donde declara el año nuevo como el 'Año del Guerrillero Heroico', y justo antes de varios recortes de prensa sobre el Asalto al Moncada con titulares que reproducen el consabido discurso del Comandante «La Historia me absolverá». El contraste entre la solemnidad del discurso institucional y la transgresión lúdica de la cultura popular afroamericana no puede ser mayor. En muchos sentidos la escena interpolada de Memorias retoma el espíritu de uno de los primeros documentales de Guillén Landrián, Los del baile (1965), consistente en escenas de los habaneros bebiendo y bailando al ritmo también del "mozambique's. Toda esta reivindicación de lo puramente lúdico e improductivo se desviaba

\footnotetext{
${ }^{8} \mathrm{Si}$, como se desprende de la prensa gubernamental, el mozambique había sido un encargo de Fidel para inspirar a los trabajadores voluntarios a tomar parte en la cosecha anual de azúcar, Los del baile es un documental completamente alejado de la euforia política que dominaba la escena política y cultural, recreándose, como antes había hecho la también censurada PM (1961), de Orlando Jiménez Leal y Saba Cabrera Infante, en el componente lúdico de la vida cotidiana y situándose, por lo tanto, en las antípodas de la visión mesiánica asignada al cine, especialmente al documental, por el gobierno revolucionario. Dylon Robbins se ha referido a Los del baile como una «amplia enciclopedia visual de movimientos, de
} 
peligrosamente de los documentales de propaganda oficiales, que subrayaban de forma beligerante los esfuerzos por aumentar la producción como una nueva manifestación de la lucha contra el imperialismo. Su inserción, pues, en medio de segmentos asociados a la metanarrativa épica de la Revolución y protagonizados por su Líder Máximo, suponen una clara provocación que cuadra muy bien a la estructura contrapuntística del montaje.

Pero como en sus documentales anteriores, la impresión que comunica este nuevo cortometraje de Guillén Landrián no es la de una disidencia abierta, sino la de una indeterminación extrema basada en un contrapunto, que, a diferencia, de los documentales propagandísticos del momento, carece por lo general de síntesis final. Visto desde una perspectiva contemporánea, sin embargo, Desde La Habana: ¡1969! adquiere una significación demoledora, lo que explicaría la conmoción causada tras su exhibición en la Muestra de Nuevos Realizadores en 2003. La repetición constante de la metanarrativa histórica revolucionaria acaba por producir algo parecido a un mito de identidad, que el propio filme desmonta al incorporarlo dentro de una lógica del caos que invalida cualquier pretensión épica o teleológica. La trama didáctica se disuelve asimismo en una esquizofrenia audiovisual que sintetiza en unos minutos el periodo republicano, los gobiernos de Machado y Batista, el asalto al Moncada y al Palacio Presidencial, el triunfo de la Revolución, y las campañas del Cordón de La Habana, de la Zafra de los Diez Millones y de los 100 Años de Lucha, entre otros muchos referentes históricos. Hacia el final escuchamos un extracto del Diario de Bolivia del Che, donde teme morir, no como resultado de la lucha armada, sino de su condición asmática. El filme culmina en una superposición de fragmentos del discurso pronunciado por Fidel en la Plaza de la Revolución recordando la muerte del guerrillero, sobre algunas de sus imágenes de juventud, culminando en un apresurado «PATRIA O MUERTE» seguido del rótulo «FIN» con un fondo sonoro consistente ya en puro ruido.
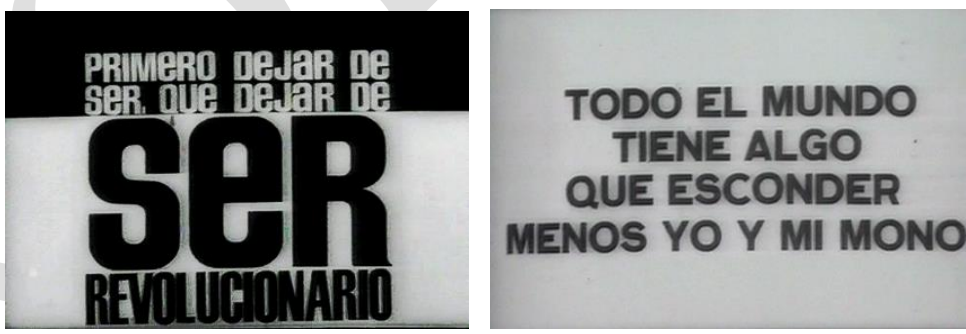

Figura 6. Contraste entre la «claridad feliz» (Barthes, 1957: 239) de los eslóganes revolucionarios (izquierda) y la ambivalencia surrealista de muchos intertítulos interpolados en Desde La Habana (derecha).

No es de sorprender que el ICAIC nunca exhibiera el documental. Lo que sí es discutible es que lo hiciera por considerarlo «incoherente con el contexto» (Petusky et al., 2005: 4). Desde La Habana es, entre otras muchas cosas, una magnífica transposición cinematográfica de la histeria colectiva, el reduccionismo (y consiguiente) manipulación de la historia y del impostado fervor que se vieron

cuerpos relajados, del desorden sincronizado y del exceso del goce público» (2013). El filme corrió la misma suerte que $P M$ y fue prohibido, pero a diferencia del cortometraje de Saba Cabrera Infante y Orlando Jiménez Leal, que, a pesar de su corta vida, llegó a ser emitido por el canal 2 de la televisión cubana, el de Guillén Landrián nunca se llegó a estrenar. 
avocados a asumir los 'trabajadores de la cultura' en aquellos años. El filme se realiza en pleno estallido del Caso Padilla, cuando el enfrentamiento entre el gobierno y los intelectuales menos afectos al régimen alcanza su máxima tensión. Y esto era precisamente lo que lo hacía intolerable en el ámbito de la cultura institucional. Esta evaluación negativa no hizo sino empeorar tras completar el que sería uno de sus últimos trabajos: Taller Línea y 18 (1971), donde muestra a los trabajadores de un taller de reparación de autobuses en asambleas públicas rechazando, por razones personales, su nominación a cargos del Partido Comunista. A lo largo del cortometraje se repite un intertítulo amenazante para el espectador: «¿Está Ud. dispuesto a ser analizado por esta asamblea?». La película termina con los mismos rótulos que algunos de sus filmes anteriores: «FIN / PERO / NO / ES / EL / FIN», siguiendo así la tendencia a la autorreferencialidad y los guiños intertextuales (e intratextuales) que marcaron toda su obra. Como sugiere Julio Ramos, en Taller Línea y 18 «el realizador ironiza la relación entre el ensamblaje industrial, el montaje fílmico y una asamblea obrera, todo bajo el signo de una disonancia radical que captó rápidamente la atención de los censores» (2013a). Estos interpretaron la ironía como un sabotaje al propósito del documental (la propaganda didáctica), invirtiendo así el papel asignado por el Estado al cine como su principal aliado mediático.

\section{Conclusión: Fin... pero no es EL FIN}

Si el medio cinematográfico constituye el discurso multimedial por excelencia (Pethö, 2003: 183), en los documentales realizados por Guillén Landrián a finales de los 60 la multimedialidad adquiere un rango patológico solo antes visto en las manifestaciones más extremas del cine-collage. Aunque formalmente los recursos sean a veces similares a los que empleaba Santiago Álvarez por aquellos años, ideológicamente media un abismo entre las obras del más oficialista y las del más maldito de los documentalistas del ICAIC. Al discurso monológico, afirmativo y panfletario de Álvarez, opone Guillén Landrián otro basado en la polifonía, la ambigüedad y la duda. Frente la exaltación de lo colectivo encarnado por abstracciones como «el Pueblo», «la Patria»y el «Hombre Nuevo», busca rescatar al individuo en su contexto, pero también en su singularidad plena.

No es de extrañar, pues, que su obra fuera censurada e ignorada hasta muy recientemente; como tampoco que en los últimos años haya servido de referente obligado para los nuevos realizadores cubanos, cada vez menos dependientes del aparato del Estado. En «Exhumaciones de Nicolás Guillén Landrián» Reyes ha estudiado la influencia de su obra en Juan Carlos Cremata (La época, el Encanto y Fin de Siglo, 1999), Gustavo Pérez (Sola, 2003; Despertando a Quan Tri, 2004), Susana Barriga (Patria, 2007), Fernando Pérez (Suite Habana, 2003), Rigoberto Jiménez (Los ecos de la niebla, 2004; Como aves del monte, 2005), Ariagna Fajardo (El círculo, 2011), Armando Capó (La marea, 2009; Nos quedamos, 2011), Jorge de León (La niña mala, 2011; La felicidad, 2012), y Eliécer Jiménez (Usufructo, 2011). Habría que añadir a la lista el nombre de Esteban Insausti, cuyo cortometraje Existen (2005), sobre los locos habaneros, no solo está dedicado a la memoria de Guillén Landrián, sino que evoca magistralmente su legado. Siguiendo la estela abierta por su cine transgresor e irreverente, la obra de los nuevos documentalistas se caracteriza por la innovación formal y el rechazo 
a la teleología revolucionaria signada por un nacionalismo autoritario. No hay rastro en ellos del dogmatismo propio del documental épico revolucionario. Por el contrario, reivindican las subjetividades marginales, con la consiguiente problematización del sujeto popular, y el abandono del punto de vista dogmático y didascálico propio del documental institucional.

\section{Bibliografía}

ARAY, Edmundo (1983): Santiago Álvarez: Cronista del Tercer Mundo. Caracas, Cinemateca Nacional.

ARTHUR, Paul (2000): «The Status of Found Footage», Spectator, 20/1, pp. 57-69.

BARTHES, Roland (1957): Mitologías. Trad. de Martí Soler. México, Siglo XXI, 1980.

Brown, Charles J., y Lago, Armando M. (1991): The Politics of Psychiatry in Revolutionary Cuba. Washington D. C., Freedom House of Human Rights.

Brown, Tom (2013): Breaking the Fourth Wall: Direct Address in Cinema. Edimburgo, Edinburgh University Press.

CASTRO RUZ, Fidel (1991): Palabras a los intelectuales. La Habana, Biblioteca Nacional José Martí. ChanAn, Michael (1980): BFI Dossier Number 2. Santiago Álvarez. Londres, British Film Institute.

DÄLlENBACH, Lucien (1977): El relato especular. Trad. de Ramón Buenaventura. Madrid, Visor, 1991.

DeleuZE, Gilles (1984): La imagen movimiento. Estudios sobre cine 1. Trad. de Irene Agoff. Barcelona, Paidós.

ElenA, Alberto (2006): «Coffea Arábiga: De incierta manera», en Julie AMIOT y Nancy BeRTHIER, eds., Cuba: cinéma et révolution. Lyon, Le Grimh, pp. 69-78.

ÉvorA, José Antonio (1990): «Santiago Álvarez et le documentaire», en Paulo Antonio PARANAGUÁ, ed., Le cinema cubain, París, Centre Georges Pompidou, pp. 123-30.

García Borrero, Juan Antonio (2012): «Enciclopedia Popular del ICAIC (1961-1963)», Cine cubano: la pupila insomne, en https://cinecubanolapupilainsomne.wordpress.com/2012/07/12/ enciclopedia-popular-del-icaic-1961-1963/ (última consulta, 15-7-2016).

GUERRA, Lillian (2012): Visions of Power in Cuba: Revolution, Redemption, and Resistance, 1959. 1971. Chapel Hill, The University of North Carolina Press.

Gutiérrez AleA, Tomás (1969): «Respuesta a Cine Cubano», Cine cubano, 54/55, pp. 22-27.

JuAN-NAVARRO, Santiago (2008): «¿100 años de lucha por la liberación?: Las Guerras de Independencia en el cine de ficción del ICAIC», Archivos de la Filmoteca, 59, pp. 142-161.

MrAZ, John (1990): «Santiago Álvarez: From Dramatic Form to Direct Cinema», en Julianne BuRTON, ed., The Social Documentary in Latin America. Pittsburgh, University of Pittsburgh Press, pp. 131-49.

NicHOLS, Bill (1997): La representación de la realidad: cuestiones y conceptos sobre el documental. Trad. de Josetxo Cerdán y Eduardo Iriarte. Barcelona, Paidós, 1997. 
ORTEGA, Ma Luisa (2009): «De la certeza a la incertidumbre: collage, documental y discurso político en América Latina», en Sonia GArcía LóPEZ y Laura Gómez VAquero, eds., Piedra, papel y tijera: el collage en el cine documental. Madrid, Ocho y Medio, pp. 101-137.

PETHÖ, Ágnes (2003): «Las figuras reflexivas de la intermedialidad en la película. El cine como espejo de las artes / las artes en el espejo del cine», Signa, 12, pp. 183-207.

Petusky Coger, L. et al (2005): «Entrevistas: El cine postergado», Cubaencuentro.com, 2 de septiembre, en http://arch1.cubaencuentro.com/entrevistas/20050722/74540a9e00385c591a45b ac12d946245/1.html (última consulta, 15-7-2016).

RAmos, Julio (2013a): «Los archivos de Guillén Landrián: cine, poesía y disonancia», La fuga, primavera, en http://www.lafuga.cl/los-archivos-de-guillen-landrian/659 (última consulta, 15-72016).

(2013b): «Regresar a La Habana con Guillén Landrián: Entrevista a Gretel Alfonso», La fuga, primavera, en http://www.lafuga.cl/regresar-a-la-habana-con-guillen-landrian/662 (última consulta, 15-7-2016).

REED, Roger (1991): The Cultural Revolution in Cuba. Ginebra, Latin American Round Table.

REYES, Dean Luis (2010): La mirada bajo asedio. El documental reflexivo cubano. Santiago de Cuba, Oriente.

— (2013): «Exhumaciones de Nicolás Guillén Landrián», La fuga, primavera, en http://www. lafuga.cl/exhumaciones-de-nicolas-guillen-landrian/660 (última consulta, 15-7-2016).

RIST, Peter. (2007): «Agit-prop Cuban Style. Master Montagist Santiago Álvarez», Offscreen 11/3, en http://offscreen.com/view/agit_prop_cuban_style (última consulta, 15-7-2016).

RobBins, Dylon. «Los del baile: pueblo, producción, performance», La fuga, primavera, en http://www.lafuga.cl/los-del-baile/658 (última consulta, 15-7-2016).

SCHRÖTER, Jens (2010): «The Politics of Intermediality», Acta Universitatis Sapientiae, Film and Media Studies, 2, pp. 107-124.

VALLE DÁviLA, Ignacio del (2013): «Crear dos, tres... muchos collages, ES LA CONSIGNA. El collage en el documental latinoamericano de descolonización cultural», Cinémas d'Amérique latine, 21/1, pp. 42-55.

VV. AA. (1971): «Declaración del Primer Congreso Nacional de Educación y Cultura», Casa de las Américas, 65/66, pp. 4-19.

ZAYAS, Manuel (2010): «Nicolás Guillén Landrián: muerte y resurrección», Cinémas d’Amérique latine, 18/1, pp. 121-135. 